\title{
Desorption of the Exotic Fruit Jujube (Ziziphus Jujube Mill) of Bulgarian Origin
}

\author{
Albena Durakova ${ }^{1, *}$, Adelina Bogoeva ${ }^{2}$, Velichka Yanakieva ${ }^{3}$, Tzvetana Gogova ${ }^{4}$, and \\ Kornelia Choroleeva ${ }^{5}$ \\ ${ }^{1 *}$ Department of Process Engineering, University of Food Technologies - Plovdiv, 26 Maritza Blvd. \\ BG-4002 Plovdiv, Bulgaria \\ ${ }^{2}$ Department of Mechanical and Instrument Engineering, Technical University - Sofia, Plovdiv \\ Branch, 25 Tsanko Duistabanov Str., Plovdiv 4000, Bulgaria \\ ${ }^{3}$ Department of Microbiology, University of Food Technologies - Plovdiv, 26 Maritza Blvd. BG- \\ 4002 Plovdiv, Bulgaria \\ ${ }^{4}$ Department of Technology of Grain, Fodder, Bread and Confectionery Products, University of Food \\ Technologies - Plovdiv, 26 Maritza Blvd. BG-4002 Plovdiv, Bulgaria \\ ${ }^{5}$ Kornelia Choroleeva - Language Training Centre, University of Food Technologies - Plovdiv, 26 \\ Maritza Blvd. BG-4002 Plovdiv, Bulgaria
}

\begin{abstract}
The present study determined the physico-chemical parameters of the exotic fruit jujube (Ziziphus jujube mill) of Bulgarian origin - $\mathrm{pH}$ of 4.62 , refractometric dry matter of $31.6 \%$, dry matter (in weight) of 36.78 $\%$, TTA (total titratable acidity) - citric acid - of $0.67 \%, 0.70 \%$ malic acid, $65.95 \%$ moisture, $0.78 \%$ fibre, $1.41 \%$ protein, $23.65 \%$ carbohydrate, $0.24 \%$ fat and energy value of $428.44 \mathrm{~kJ} / 102.4 \mathrm{kcal}$. Equilibrium moisture content and monolayer moisture content were established for desorption concerning eight water activities in the $0.1-0.9$ range and the temperatures of $10{ }^{\circ} \mathrm{C}, 25^{\circ} \mathrm{C}$ and $40{ }^{\circ} \mathrm{C}$. The coefficients of the modified Oswin, Chung-Pfost, Halsey and Henderson models were obtained statistically. The modified Halsey model is recommended as a description of the desorption isotherms of jujube (Ziziphus jujube mill) since it corresponds to the criteria for model assessment and suitability. Via BET model linearization, the values of the monolayer moisture content for desorption at the temperatures of $10{ }^{\circ} \mathrm{C}-5.41 \%$ d.b., $25{ }^{\circ} \mathrm{C}-4.65 \%$ d.b. and $40{ }^{\circ} \mathrm{C}-5.08 \%$ d.b were determined.
\end{abstract}

Key words: jujube (Ziziphus jujube mill), physico-chemical parameters, sorption characteristics

\footnotetext{
* Corresponding author: aldurakova@abv.bg
} 


\section{Introduction}

Contemporary medicinal practices apply various methods and techniques whose efficiency was recognized and tested in China and other Asian countries thousands of years ago. The world has long acknowledged the extraordinary refreshing effects of a great number of fruits, vegetables, and herbs, including grapes, apricots, carrots, goji berry, ginkgo biloba, ginseng, pumpkin, thyme, St. John's wort, and many others [1-4].

According to Jinous Asgarpanah and Elaheh Haghighat, among the first five healthiest medicinal plants in the world we find the jujube (Chinese date) which is less common in Bulgaria although the Chinese started growing and using the plant more than 6000 years ago. There are more than 50 varieties of jujube but Ziziphus jujube Mill is the most popular and useful one [5].

Jujube (Zizyphus jujuba Mill) is among the four staple agricultural species in China where it is grown on two-million-decare areas. In these areas, there is extremely low incidence of diseases and a specific resistance to the development of respiratory tract illnesses. This may be the reason why the local population refers to the fruit of the jujube plant as "chest fruit". Selective breeding has led to the growth of bigger jujube plants whose sugar content can be three times as high as that of the ordinary jujube.

It is an interesting fact that for medicinal and prophylactic effects almost all parts of the jujube plant can be used: roots, stem, bark, leaves and fruit. It is not surprising that the fruit of the jujube is most popular because it is very tasty. It has a sweet or a slightly sweet-sour taste of the light green pulp whose consistency resembles that of bread. The jujube fruit is extremely high in flavonoids, saponins, sugars, vitamin A, vitamins $\mathrm{C}$ and B2, minerals (calcium, iron, and phosphorus) [6]. The vitamin $\mathrm{C}$ content of the jujube plant is between 8 - 18 times as high as that of tomatoes and citrus fruit and about as 200 times as high as that of apples, peaches and pears. The amount of vitamin C is extremely high - between $10-20$ times (reaching $1700 \mathrm{mg} / 100 \mathrm{~g}$ ) as high as that of the fruits boasting with their vitamin $\mathrm{C}$ content, i.e. fuzzy kiwifruit, lemons, oranges and blackcurrant. The jujube contains great amounts of P-active compounds (305-1230 mg/100 g), proteins, malic acid, pectin, tannins and rutin [7]. It is rich in carbohydrate whose composition, depending on jujube variety, ranges between $20 \%$ - $40 \%$ (over $60 \%$ in dried fruit). Such vitamin-active substances are also represented by a group of bioflavonoids (rutin, citrin, catechins, etc.) which have a positive multi-level effect on the human organism: resistance to free radicals (because of high antioxidant activity), improvement of blood cell elasticity, anti-inflammatory effect, blood pressure regulation, maintenance of the active form of vitamin $\mathrm{C}$, etc. [8,9]. Therefore, the jujube plant is a valuable source of phytochemicals, bioactive substances, vitamins, etc., which makes it useful in the treatment and prophylaxis of various diseases [10].

The literature review did not show the existence of data on the physico-chemical parameters and desorption characteristics of Bulgaria-grown jujube (Zizyphus jujuba Mill), which helped identify the following objectives of the present study: analysis of the physicochemical parameters and desorption characteristics of the exotic plant jujube (Ziziphus jujube mill) of Bulgarian origin.

\section{Materials and Methods}

\subsection{Materials}

The object of the present study is jujube (Zizyphus jujuba Mill) of Bulgarian origin supplied by an experimental facility in the town of Assenovgrad, Bulgaria. 


\subsection{Methods}

pH - Bulgarian State Standard (BSS) 11688:1993 [11];

Dry matter, refractometric (Re) - BSS EN 12143:2000 [12],

Dry matter, in weight - BSS EN 12145:2000 [13];

TTA (total titratable acidity) BSS 6996:93 [14];

- $\quad$ Citric acid

- $\quad$ Malic acid

Fibre - BSS 11374:1986 [15];

Fat content, (\%) - Soxhlet method via solvent extraction with petroleum ether. BSS 6997:1984 [16];

Carbohydrate - BSS 7169:1989 [17];

Protein - Direct Kjeldahl method analysis (determination of nitrogen content/ nitrogen determination method) - Regulation (EC) №152/2009 [18];

Energy value - Regulation 1169:2011, Appendices IVX ; XV [19].

Moisture, (\%) of the products studied - standard method via drying of $5 \mathrm{~g}$ of flour at $105^{\circ} \mathrm{C}$ to constant weight, according to $\mathrm{AOAC}, 1990$ [20].

Determination of microbiological parameters:

Determination of Escherichia coli, according to BSS EN ISO 16649-2:2014 [21];

Determination of Salmonella sp., according to BSS EN ISO 6579-1:2017 [22];

Determination of coagulase-positive staphylococci, according to BSS EN ISO 68881:2005 [23];

Determination of total number of mesophilic aerobic and facultative anaerobic bacteria, according to BSS EN ISO 4833-1:2014 [24];

Determination of mould and yeast, according to BSS EN ISO 21527-2:2011 [25].

In order to analyse sorption isotherms, we used the static gravimetric method recommended for food products by Project COST 90. Due to the high initial moisture content of jujube, the samples were not moistened in advance and, after deseeding, they were weighted as per $1 \pm 0.02 \mathrm{~g}$ in weighing bottles. Weighing bottles are placed in hygrostats above saturated solutions of 8 salts $\left(\mathrm{LiCl}, \mathrm{MgCl}_{2}, \mathrm{~K}_{2} \mathrm{CO}_{3}, \mathrm{NaBr}, \mathrm{CH}_{3} \mathrm{COOK}\right.$, $\mathrm{NaCl}, \mathrm{KCl}, \mathrm{MgNO}_{3}$ ) maintaining media with constant water activities, from 0.1 to 0.9 [26]. For high water activities, $\left(\mathrm{a}_{w}>0.70\right)$ in hygrostats thymol crystals are introduced to prevent against microbiological deterioration. Hygrostats are tempered in thermostats at temperatures of 10,25 and $40 \pm 0.2{ }^{\circ} \mathrm{C}$. When equilibrium is reached (within 20 days), the moisture content of each sample is determined via a drying method $\left(105^{\circ} \mathrm{C}\right.$ for $\left.24 \mathrm{~h}\right)$ as a mean value of three iterations [20].

All analyses were conducted in triplicate runs.

The experimentally obtained sorption isotherms were described with the help of the modified three-parameter models recommended for products of plant origin in Standard 245D of the American Society of Agricultural Engineers (ASAE) [26]:

Modified Chung-Pfost

$$
a_{\mathrm{W}}=\exp \left[\frac{-A}{\mathrm{t}+B} \exp (-C M)\right]
$$

Modified Halsey

$$
a_{\mathrm{W}}=\exp \left[\frac{-\exp (A+B t)}{M^{C}}\right]
$$

Modified Oswin

$$
M=(A+B t)\left(\frac{a_{\mathrm{w}}}{1-a_{\mathrm{w}}}\right)^{C}
$$




$$
\text { Modified Henderson } \quad 1-a_{\mathrm{w}}=\exp \left[\left(-A(t+B) M^{C}\right]\right.
$$

To determine model coefficients, we applied the least squares method using a non-linear regression program. Model suitability criteria were the values of mean relative error $\mathrm{P}$ [\%] and standard error (SEM) [27, 28]:

$$
\begin{aligned}
& P=\frac{100}{N} \sum\left|\frac{M_{\mathrm{i}}-\hat{M}_{\mathrm{i}}}{M_{\mathrm{i}}}\right| \\
& S E M=\sqrt{\frac{\sum\left(M_{\mathrm{i}}-\hat{M}_{\mathrm{i}}\right)^{2}}{\mathrm{~d} f}} \\
& e_{\mathrm{i}}=M_{\mathrm{i}}-\hat{M}_{\mathrm{i}}
\end{aligned}
$$

where $M_{i}$ and $\widehat{M}_{i}$ are the experimentally obtained equilibrium moisture content value as calculated by the model, $\mathrm{N}$ being the number of test points and $\mathrm{d} f$ being the degree of freedom (number of test points minus number of constant values in the model).

To calculate monolayer moisture content, we used the linear transform on the basis of the BET (Brunauer-Emmett-Teller) model [29].

BET

$$
M=\frac{M_{m} C a_{w}}{\left(1-a_{w}\right)\left(1-a_{w}+C a_{w}\right)}
$$

where $M_{m}$ is monolayer moisture content, \% d.b.; $C$ - constant value.

\section{Results and Discussion}

The experimentally obtained results concerning the physico-chemical parameters of the exotic plant jujube (Ziziphus jujube mill) are presented in Table 1. The analysis shows that the plant is rich in dry matter, which accounts for the bready consistency of the pulp [6]. The results also demonstrate the presence of citric acid and malic acid. The differences in the data found in scientific literature are due to the different origin of jujube having to do with different territorial, climatic and soil characteristics. Carbohydrate content, $23.56 \%$, is within the range of the values reported by scientific literature [7].

Table 1. Physico-chemical parameters of Jujube (Ziziphus jujube mill)

\begin{tabular}{|c|c|c|}
\hline № & Physico-chemical parameter & Value for $\mathbf{1 0 0} \mathbf{g}$ \\
\hline 1. & $\mathrm{pH}$ & 4.62 \\
\hline 2. & Dry matter, refractometric (Re) & $31.6 \%$ \\
\hline 3. & Dry matter, in weight & $36.78 \%$ \\
\hline 4. & TTA (total titratable acidity) & \\
& - as citric acid & $0.67 \%$ \\
& - as malic acid & $0.70 \%$ \\
\hline 5. & Fibre & $0.78 \%$ \\
\hline 6. & Fat & $0.24 \%$ \\
\hline 7. & Carbohydrate & $23.65 \%$ \\
\hline 8. & Protein & $1.41 \%$ \\
\hline 9. & Moisture & $65.98 \%$ \\
\hline 10. & Energy value & $428.44 / 102.4$ \\
& & $\mathrm{~kJ} / \mathrm{kcal}$ \\
\hline
\end{tabular}

On receiving the raw material from the experimental facility, we analysed its microbiological profile. We determined the following microbiological parameters: 
total number of mesophilic aerobic and facultative anaerobic bacteria $-1.7 \times 10^{4}$, fungi -1.5 $\mathrm{x} 10^{3}$, lack of Salmonella sp., presence of Escherichia coli, coagulase-positive staphylococci and yeast - below the acceptable level. The results from the analysis demonstrate that the product is not microbiologically contaminated, which makes us believe that it is suitable for direct consumption.

The experimentally obtained values of the equilibrium moisture content of jujube (Ziziphus jujube mill) for desorption at the temperatures of $10{ }^{\circ} \mathrm{C}, 25{ }^{\circ} \mathrm{C}$ and $40{ }^{\circ} \mathrm{C}$ as well as the eight values of the relative humidity of air in the $0.1-0.9$ range are presented in Table 2.

Table 2. Equilibrium moisture content $M, \%$ d.b. for different temperatures $t\left({ }^{\circ} \mathrm{C}\right)$ and water activities $a_{w}$ in desorption

\begin{tabular}{|c|c|c|c|c|c|c|c|c|c|}
\hline \multirow[t]{2}{*}{ Sel } & \multicolumn{3}{|c|}{$10^{\circ} \mathrm{C}$} & \multicolumn{3}{|c|}{$25^{\circ} \mathrm{C}$} & \multicolumn{3}{|c|}{$40^{\circ} \mathrm{C}$} \\
\hline & $a_{\mathrm{w}}$ & $\mathrm{M}^{*}$ & $\mathrm{sd}^{* *}$ & $a_{\mathrm{w}}$ & $\mathrm{M}^{*}$ & $\mathrm{sd}^{* *}$ & $a_{\mathrm{w}}$ & $\mathrm{M}^{*}$ & $\mathrm{sd}^{* *}$ \\
\hline $\mathrm{LiCl}$ & 0.113 & 8.54 & 0.05 & 0.113 & 8.23 & 0.11 & 0.112 & 5.59 & 0.06 \\
\hline $\mathrm{CH}_{3} \mathrm{COOK}$ & 0.234 & 8.81 & 0.13 & 0.225 & 8.36 & 0.16 & 0.201 & 7.45 & 0.09 \\
\hline $\mathrm{MgCl}_{2}$ & 0.335 & 8.87 & 0.28 & 0.328 & 8.84 & 0.14 & 0.316 & 7.96 & 0.12 \\
\hline $\mathrm{K}_{2} \mathrm{CO}_{3}$ & 0.431 & 10.73 & 0.08 & 0.432 & 9.34 & 0.09 & 0.432 & 9.08 & 0.09 \\
\hline $\mathrm{MgNO}_{3}$ & 0.574 & 12.85 & 0.14 & 0.529 & 10.83 & 0.15 & 0.484 & 9.99 & 0.08 \\
\hline $\mathrm{NaBr}$ & 0.622 & 13.77 & 0.13 & 0.576 & 11.05 & 0.14 & 0.532 & 10.12 & 0.15 \\
\hline $\mathrm{NaCl}$ & 0.757 & 23.46 & 0.24 & 0.753 & 19.06 & 0.18 & 0.747 & 15.75 & 0.08 \\
\hline $\mathrm{KCl}$ & 0.868 & 48.88 & 0.15 & 0.843 & 24.75 & 0.23 & 0.823 & 21.13 & 0.21 \\
\hline
\end{tabular}

${ }^{*}$ Mean of three replications ${ }^{* *}$ Standard deviation based on three replications

The results obtained prove a correlation typical of a number of food products studied, i.e. the increase in temperature at a constant water activity is coupled with a decrease in equilibrium moisture content $[30,31]$.

Fig. 1 presents graphically the desorption isotherm of jujube at $10{ }^{\circ} \mathrm{C}$ which makes it clear that, according to Brunauer's classification, it belongs to type III [32].

The statistical processing with the help of a non-linear regression program using the least squares method calculated the coefficients of the modified three-parameter models applied in the analysis (Table 3). We also calculated their values for mean relative error P, $\%$, and standard error SEM.

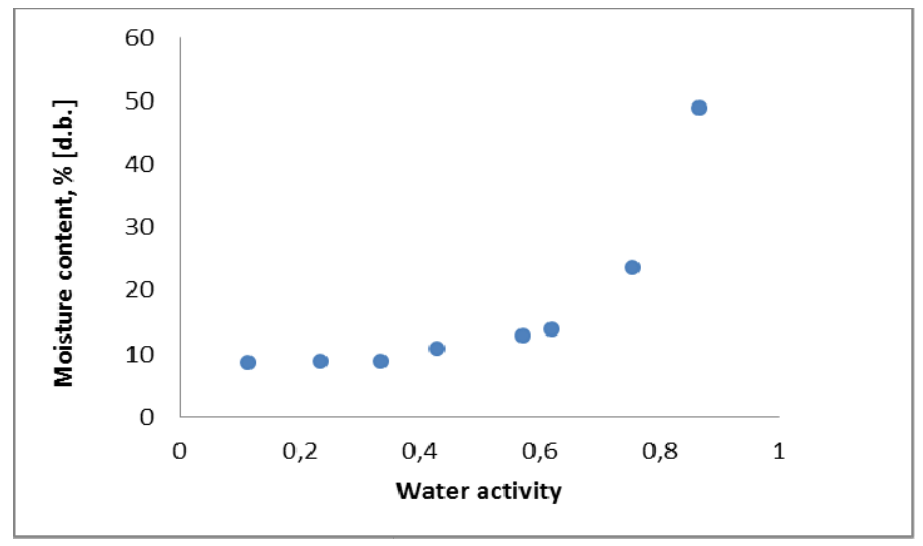

Fig. 1. Sorption isotherm of jujube at $10{ }^{\circ} \mathrm{C}$ 
Table 3. Model Coefficients $(A, B, C)$, mean relative error (P, \%), and standard error (SEM) for desorption.

\begin{tabular}{|c|c|c|c|c|c|}
\hline Model & $A$ & $B$ & $C$ & $P$ & $S E M$ \\
\hline Oswin & 15,4365 & -0.1726 & 0.5819 & 25.38 & 5.65 \\
\hline Halsey & $\mathbf{5 . 0 1 1 2 7}$ & $\mathbf{- 0 . 0 1 2 3}$ & $\mathbf{2 . 0 9 9 5}$ & $\mathbf{1 0 . 9 5}$ & $\mathbf{3 . 5 9}$ \\
\hline Henderson & 0.00015 & 7.4311 & 2.0327 & 22.85 & 6.18 \\
\hline Chung-Pfost & 578.063 & 0.1820 & 76.949 & 16.58 & 7.00 \\
\hline
\end{tabular}

The results obtained demonstrate that the lowest values of mean relative error $(\mathrm{P}, \%)$ and standard error (SEM) were calculated for Modified Halsey. Taking into account model assessment and suitability criteria, this result allows us to recommend the three-parameter Halsey model as desorption isotherm description of jujube. The other three modified models have considerably higher values which makes them unsuitable for the desorption isotherm description of the product under study.

To calculate the monolayer moisture content (MMC) of Bulgarian jujube fruit for desorption, the BET model was linearly transformed with test data for $\mathrm{a}_{w}<0.5$, as shown in Fig. 2. On the basis of linear equation coefficients, we calculated MMC values, as presented in Table 4.

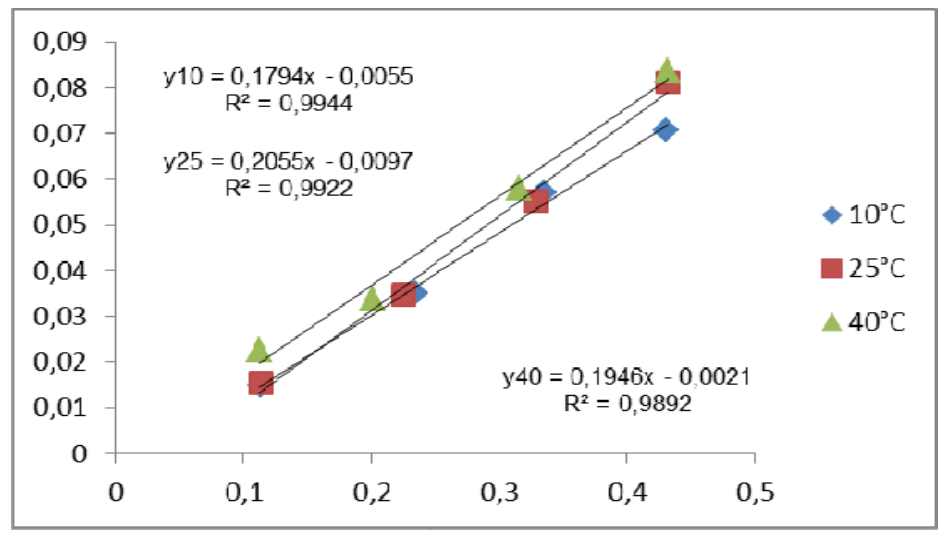

Fig. 2 BET model linearization for different temperatures in desorption

Table 4. BET monolayer moisture content, \% d.b., at different temperatures t.

\begin{tabular}{cc}
\hline$t\left({ }^{\circ} \mathrm{C}\right)$ & Desorption \\
\hline 10 & 5.41 \\
25 & 4.65 \\
40 & 5.08 \\
\hline
\end{tabular}

On the basis of the obtained results, we can conclude that there is no direct correlation between the values of monolayer moisture content and temperature for the desorption of Bulgarian jujube (Zizyphus jujuba Mill).

\section{Conclusion}

As a result of the present study, we obtained the equilibrium moisture content for desorption at $10{ }^{\circ} \mathrm{C}, 25^{\circ} \mathrm{C}$ and $40^{\circ} \mathrm{C}$ as well as the relative humidity in the $0.1-0.9$ range concerning jujube (Zizyphus jujuba Mill) of Bulgarian origin. We established that 
temperature affects the sorption capacity of jujube (Zizyphus jujuba Mill). With the increase of the latter, at a constant water activity, the values of equilibrium moisture content are lowered. This study is the first to identify the equilibrium isotherm for desorption of the fruit of exotic Bulgarian jujube (Zizyphus jujuba Mill).

The research also determined the numerical values of the coefficients of the modified three-parameter models used, as a result of which it recommends Halsey's model as regards the description of the equilibrium isotherms of the product under study. Thus, the model can be used in engineering practice for the determination of equilibrium moisture content.

Via the linearization of the Brunauer-Emmett-Teller model, the present study also calculated the monolayer moisture content (MMC) values of the product. The moisture value corresponding to $\mathrm{MMC}$ is a sorption characteristic which has a positive effect on the stability of the product. The MMC values obtained are a good foundation for subsequent detailed studies on the storage regimes and shelf life of Bulgarian jujube (Zizyphus jujuba Mill).

This study was part of the Fund Scientific Research "FS N11/20-H", director project: Assoc. Prof. PhD Albena Georgieva Durakova, University of Food Technologies - Plovdiv, Bulgaria.

\section{References}

1. I. Dimov, ICTTE (Yambol, Bulgaria), I, ISSN 1314-9474, 479-485, (2013)

2. I. Dimov, A. Krasteva. Scien. W. of UFT, LX, ISSN 1314-7102, 151-155, (2013)

3. Z. Ghouila, S. Laurent, S. Boutry, L.Vander Elst, F. Nateche, R. N. Muller, A. Baaliouamer, Fundament Appl Sci., 9 (1), 392-410, (2017).

4. Y. Choi, J. Lee, Food Chem. 114 (4), 1386-1390, (2008).

5. J.Asgarpanah, E. Haghighat. Afr J Pharm Pharmacol, 6 (31), 2332-2339, (2012).

6. A. M. Pawlowska, F. Camangi, A. Bader, A. Braca, Food Chem., 112 858-862, (2009)

7. J. Li, L. Shana, Y. Liua, L. Fana, L. Aib. Int. J. Biol. Macromol., 49, 255- 259 (2011)

8. S. M. Al-Reza, J. I. Yoon, H. J. Kim, J-S. Kim, S. C. Kang, Food Chem Toxicol, 48, 639-643, (2010)

9. H. Zhang, L. Jiang, S. Ye, Y. Ye, F. Ren, Food Chem Toxicol, 48, 1461-1465, (2010

10. M. A. Beg, U.V.S. Teotia, S, Farooq, J. Med. Plants, 4 (5), 230-233, (2016)

11. B.S. Standard, $\mathrm{pH}$, in BSS 11688:1993

12. B.S. Standard, Dry matter, refractometric, in (BSS) EN ISO 12143:2000

13. B.S. Standard, Dry matter, in weight - in (BSS) EN ISO 12145:2000

14. B.S. Standard, TTA (total titratable acidity), in BSS 6996:93

15. B.S. Standard, Fibre, in (BSS) EN ISO 11374:1986

16. B.S. Standard, Fat content, in (BSS) EN ISO 6997:1984

17. B.S. Standard, Carbohydrates in (BSS) EN ISO 7169:1989

18. B.S. Standard, Proteins, in Reglement (EO) №152/2009

19. Standard in Reglement 1169:2011. App. IVX, XV, (2011)

20. AOAC, 960.39 (Washington, DC), 15 ed. AOAC. (1990)

21. B.S. Standard, Escherichia coli, in (BSS) EN ISO 16649-2:2014

22. B.S. Standard, Salmonella spp., in (BSS) EN ISO 6579-1:2017

23. B.S. Standard, Coagulase-positive staphylococci, in (BSS) EN ISO 6888-1:2005,

24. B.S. Standard, Mesophilic aerobic and facultative anaerobic bacteria, in (BSS) EN ISO 4833-2:2014,

25. B.S. Standard, Yeasts and fungi, (BSS) EN ISO 21527-2:2011

26. ASAE. Standart 245D.5. St. Joseph, Michigan.

27. C.-C. Chen, R.V. Morey. Transactions of the ASAE, 32 (3), 983-0990, (1989)

28. C.-C. Chen, R.V. Morey. Transactions of the ASAE, 32, 999-1006, (1989)

29. L. Bell, T. Labuza, AACC, 33-36, (2000) 
30. A. Durakova, A. Bogoeva, R. Krasteva, T. Gogova, A. Krasteva and N. Georgieva, IOP Conf Ser Mater Sci Eng., 595, 012058, (2019)

31. A. L. Bogoeva, A. G. Durakova. JAFR, 2, 100026, (2020)

32. S. Brunauer, L. S. Deming, W. E. Diming, E. Troller, JACS, 62, 1723-1732, (1940) 